\title{
Impactación alimentaria como presentación de Esofagitis Eosinofílica
}

\author{
Ezita Latic Talic ${ }^{a}$, Josefa Plaza Almeida ${ }^{b}$, Elena Balmaseda Serrano ${ }^{c}$
}

\begin{abstract}
${ }^{a}$ Residente de Medicina Familiar y Comunitaria. Unidad Docente de Albacete.

b Pediatra. Centro de Salud Zona VIII (Albacete).

${ }^{c}$ Pediatra. Unidad de Gastroenterología Pediátrica. Hospital General Universitario de Albacete.

Correspondencia: Ezita Latic Talic, C/ Juan de Toledo $\mathrm{n}^{\circ} 13$, $2^{\circ}$, 02005-Albacete (España). E-mail: ezita82@hotmail.com.

Recibido el 11 de abril de 2010.
\end{abstract}

Aceptado para su publicación el 16 de mayo de 2010.

\begin{abstract}
RESUMEN
La esofagitis eosinofílica es una enfermedad inusual hasta el momento actual. Se sabe poco de su evolución natural, pero si no se trata puede provocar la formación de estenosis esofágicas. Presentamos el caso de un niño de 12 años que acude a urgencias por impactación alimentaria y presenta antecedentes de atopia y alergia, todo ello característico de esta entidad.
\end{abstract}

Palabras clave. Esofagitis, Eosinofilia.

\section{ABSTRACT}

Food impaction as a sign of Eosinophilic esophagitis

Eosinophilic esophagitis is currently an uncommon disease. Little is known on its natural progression, but if it remains untreated it may cause esophageal stenosis. We present a case of a 12 year old boy who came to the emergency department due to food impaction and who had a history of atopy and allergy, which are characteristic of this condition. Key words. Esophagitis, Eosinophilia.

\section{INTRODUCCIÓN}

La esofagitis eosinofílica es una enfermedad emergente en los últimos años, ya que no fue hasta el año 1993 cuando se citó este cuadro como entidad clínica diferenciada del resto de las enfermedades eosinófilas del tracto gastrointestinal ${ }^{1}$.

Se caracteriza por la aparición de diversos síntomas esofágicos inespecíficos, agudos y crónicos, que varían según la edad de presentación, afectando fundamentalmente a niños en edad escolar y adultos jóvenes. Los síntomas pueden estar presentes durante largos periodos antes de llegar al diagnóstico.

El diagnóstico definitivo precisa biopsia de mucosa esofágica, en la que se halla un infiltrado de más de 15 eosinófilos por campo y la exclusión de patologías más frecuentes como el reflujo gastroesofágico (RGE) o enfermedades parasitarias.

El número de casos diagnosticados se ha incrementado en los últimos años por la mejora en el conocimiento de la enfermedad.

\section{OBSERVACIONES CLÍNICAS}

Varón de 12 años con antecedentes de asma desde los 9 años, dermatitis atópica, alergia a la mostaza y episodios de abdominalgia inespecífica, así como tres episodios de impactación alimentaria que se resolvieron con vómitos espontáneos. En los antecedentes familiares destaca la presencia de alergia a gramíneas en su madre y rinoconjuntivitis alérgica en una hermana de 18 años. 
El paciente acudió a Urgencias por un nuevo episodio de impactación alimentaria, no acompañado de vómitos, pirosis ni dolor retroesternal. Tampoco presentaba dolor abdominal ni otra clínica acompañante.

En la exploración física se observó un desarrollo estatoponderal adecuado para su edad, auscultación cardiopulmonar normal, sin hallazgos significativos, salvo palidez cutánea y lesiones residuales de dermatitis atópica.

Entre las exploraciones complementarias realizadas se constató una hemoglobina de 13,8 g/L, 361.000 plaquetas y 7.400 leucocitos, con $4,7 \%$ de eosinófilos. En la bioquímica se observó: glucemia $89 \mathrm{mg} / \mathrm{dl}$, urea 21, creatinina $0,7 \mathrm{mg} / \mathrm{dl}$, GOT 25, GPT 19 y FA 191.

En la gastroscopia realizada para la extracción del bolo alimentario se apreció un esófago de aspecto traquealizado con anillos de contracción terciaria y surcos lineales longitudinales extendidos desde esófago medio hasta tercio esofágico distal, no visualizándose estenosis concéntricas. Se tomaron muestras del esófago distal para análisis anatomopatológico, el cual mostró una mucosa escamosa con hiperplasia de la basal, papilomatosis y ocasional exocitosis de linfocitos y eosinófilos, llegándose a contabilizar 13 por campo de gran aumento, focalmente.

Fue dado de alta tras extracción del cuerpo extraño, derivándose a consulta de gastroenterología infantil donde se solicitó PHmetría de 24 h, descartándose reflujo gastroesofágico.
Posteriormente fue valorado en consulta de alergia infantil, donde se realizaron pruebas alérgicas que resultaron positivas a pólenes (de gramíneas y olivo) y a diversos alimentos como mostaza, hinojo, curry, arroz y frutos secos.

El tratamiento pautado consistió en eliminar de la dieta los alimentos cuyo resultado fue positivo en las pruebas alérgicas. Además se indicó fluticasona 250 mcg (2 puff deglutidos cada 12 horas) y montelukast $10 \mathrm{mg}$ cada 24 horas, permaneciendo asintomático hasta el momento actual.

\section{COMENTARIOS}

La esofagitis eosinofílica es una inflamación crónica del esófago con alto grado de infiltración eosinofílica. La sintomatología puede ser similar al RGE, pero sin respuesta a los tratamientos propios de dicho cuadro (procinéticos, inhibidores de la bomba de protones) ${ }^{2}$. Esta falta de respuesta, unido a la coexistencia de cuadros alérgicos, hace pensar en una etiología determinada por alergenos alimentarios y ambientales, y mediada por la activación del sistema inmune, en concreto la participación de IL5 y eotaxina ${ }^{3}$, considerándose una enfermedad de origen multifactorial.

La forma de presentación varía desde síntomas digestivos inespecíficos, vómitos, dolor torácico y abdominal, hasta impactación alimentaria, como en nuestro caso, e incluso perforaciones, melenas3 y estenosis esofágicas.

El diagnóstico requiere la realización de una gastroscopia y la toma de varias biopsias en las que se
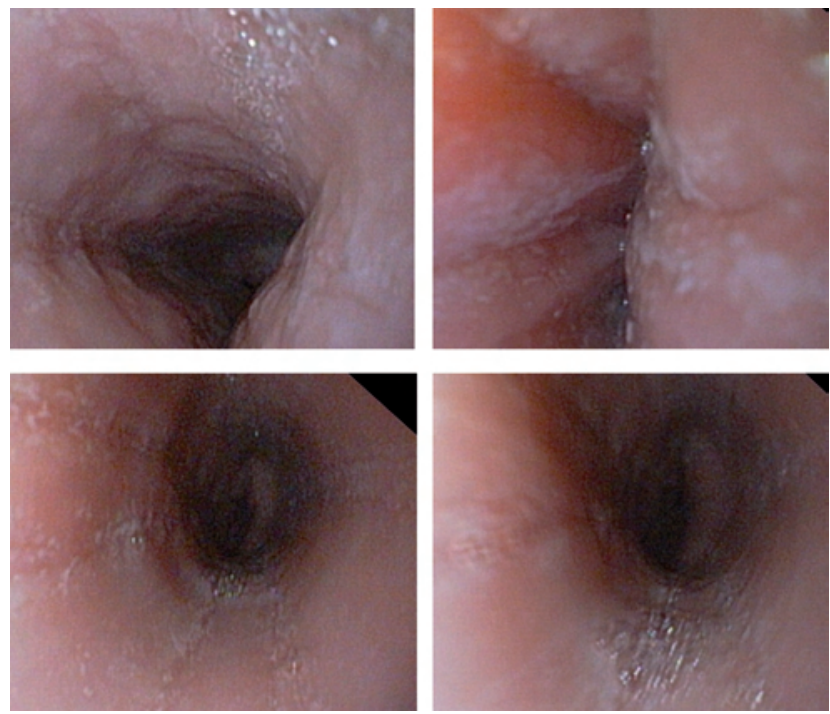

Figura 1. Imágenes obtenidas de pacientes diagnosticados de esofagitis eosinofílica en las que predominan

imágenes blanquecinas y los surcos lineales longiudinales. 
hallarían más de 15 eosinófilos por campo de gran aumento (cga) a lo largo de toda la mucosa esofágica. En nuestro caso se encontraron 13 eosinófilos/cga pero la clínica y los antecedentes alérgicos eran muy compatibles con esta entidad.

Otra de las pruebas diagnósticas imprescindibles es la pHmetría para descartar RGE. La enfermedad por RGE cursa con eosinófilos en la mucosa esofágica en número menor de 10 eosinófilos por campo de gran aumento y dicho incremento se halla fundamentalmente en el tercio esofágico distal ${ }^{4}$.

La presencia de eosinofilia periférica es variable, encontrándose en la mitad de los pacientes. En nuestro caso la analítica en el momento del diagnóstico no mostró una gran eosinofilia, pero en un hemograma previo se halló eosinofilia de hasta el $11 \%$.

El abordaje terapéutico comienza con la restricción dietética de los alergenos implicados, seguido del tratamiento farmacológico con corticoides deglutidos (fluticasona) o sistémicos (metilprednisolona), inhibidores de los leucotrienos (montelukast) y anticuerpos anti-interleucina 5 (mepolizumab), así como dilataciones esofágicas endoscópicas en los casos necesarios.
En conclusión, la esofagitis eosinofílica se debe sospechar en niños y adultos jóvenes con síntomas digestivos (impactación esofágica, clínica de RGE) y antecedentes de alergias. Se trata de una enfermedad emergente con pronóstico desconocido en la que se espera hallar nuevas medicaciones que consigan una remisión tanto clínica como histológica a largo plazo.

\section{BIBLIOGRAFÍA}

1. Attwood SE, Smyrk TC, Demeester TR, Jones JB. Esophageal eosinophila whit dysphagia. A distinct clinicopathologic syndrome. Dig Dis Sci.1993; 38:109-16.

2. Martín de Capri J, Gómez Chiari M, Castejón Ponce E, Masiques Mas ML, Vilar Escrigas P, Varea Calderón V. Aumento del diagnóstico de esofagitis eosinofílica en nuestro medio. An Pediatr (Barc). 2005; 62:333-9.

3. Ballón Hurtado AE, Encinas Bascones A, Bascones Marinez MA. Esofagitis eosinofílica: a propósito de un caso. Rev Pediatr Aten Primaria. 2009; 11:625-30.

4. Futura GT, Liacouras CA, Collins MH, Gupta SK, Justinich C, Putnam PE, et al. Eosinophilic Esophagitis in children and adults: a systematic review and consensus recommendations for diagnosis and treatment. Gastroenterol. 2007; 133:1342-63. 